Canadian Studies in Population, Vol. 31(1), 2004, pp. 83-107

\title{
Age at Marriage, Contraceptive Use and Abortion in Yemen, 1991-1997
}

\author{
T S Sunil \\ Dept. of Sociology and Social Work \\ University of Texas at San Antonio \\ San Antonio, Texas \\ Vijayan K. Pillai \\ School of Social Work \\ University of Texas at Arlington \\ Arlington, Texas
}

\begin{abstract}
This paper attempts to examine the extent of influence of the three components of fertility, age at marriage, extent of modern contraceptive use and the level of abortion on fertility in the Republic of Yemen and to explore the impact of a selected set of demographic and socioeconomic variables on the three fertility components. This study uses data from Demographic and Health Surveys (DHS) conducted in Yemen in 1991/1992 and 1997. The results from this study present empirical evidence of an onset of fertility decline in the Republic of Yemen. An important component of this decline is delayed age at marriage. There has been an increase in modem contraceptive use during the last decade. However, these methods are not widely used at early stages of family formation. The most common method of family limitation among women with large families is abortion. There has been very little change if any in the widespread occurrence of abortion during the last decade. There exist significant urban-rural differences in the levels of contraceptive use and abortion. Improvements in women's education and modern sector labor participation are crucial for increasing age at marriage, and level of contraceptive use and for reducing the prevailing level of abortion.
\end{abstract}

Key Words: Age at marriage, contraceptive use, abortion, Yemen, family limitation, fertility. 


\section{Résumé}

Cet article tente d'examiner la portée de l'influence de trois composantes de la fécondité, à savoir l'âge au mariage, la mesure dans laquelle les méthodes de contraception modernes sont utilisées et le taux d'avortements dans la République du Yémen. L'article explore aussi l'impact d'un ensemble choisi de variables socio-économiques sur les trois composantes de fécondité. Cette étude utilise les données provenant de Programmes d'enquêtes démographiques et sanitaires menés au Yémen en 1991-1992 et en 1997. Les résultats de cette étude indiquent de façon empirique un début de baisse de fertilité dans la République du Yémen. Une composante importante de cette baisse est l'âge plus avancé au mariage. Au cours de la dernière décennie, il y a eu une plus grande utilisation de méthodes de contraception modernes, bien que ces méthodes ne soient pas largement utilisées pendant la première période de formation de la famille. La méthode la plus courante de limitation des naissances chez les femmes qui ont une famille nombreuse est l'avortement. Il y a eu très peu de changements dans le nombre d'avortements au cours des dix dernières années. Il y a cependant des différences significatives entre la vie urbaine et la vie rurale quant à l'utilisation de contraception et au nombre d'avortements. Il est crucial d'apporter des améliorations à l'éducation des femmes et de les faire participer au marché du travail pour hausser l'âge au mariage et augmenter l'utilisation de méthodes de contraception et réduire le taux d'avortements.

Mots-clés : âge au mariage, utilisation de contraception, avortement, Yémen, limitation des naissances, fécondité

\section{Introduction}

It has been long believed that Middle Eastern fertility levels are likely to remain stubbornly high for a variety of cultural reasons. In particular, in the presence of religious and cultural values that strongly discourage the use of birth control methods, population explosion in the Middle East is predicted to occur (Rashad, 1999). In addition, the Middle Eastern region is expected to part from the rest of the world without having participated in the process of demographic transition process. Thus, the Middle Eastern region is of theoretical interest because current theories such as the demographic transition theory appear to be inadequate in predicting the course of demographic changes in this region. Secondly, the Middle East is of policy interest as there is widespread concern about the political, social and economic consequences of a "demographic time bomb" for the Arab region and the rest of the world. 
Age at Marriage, Contraceptive Use and Abortion in Yemen, 1991-1997

Against wide spread predictions that natural fertility regimes in the Middle Eastern countries will persist in the foreseeable future, almost all countries in the Middle East have experienced fertility declines in recent decades (Rashad, 1999). The fertility decline started in Muslim societies of North Africa such as Egypt, Tunisia and Morocco. Perhaps the first country to register fertility decline was Lebanon. Tunisia and Egypt followed. Approximately ten to fifteen years after the start of the Tunisian fertility transition, Algeria, with a high fertility rate even by fertility level standards for the Arab region, registered declines in fertility. Within a span of 20 years, the total fertility rate in Algeria fell by 3 children (Rashad, 2000). By 1995 all Arab states had undergone some decline in fertility (Rashad, 2000). Currently, fertility has fallen in every Arab country except Yemen. Fertility rates in Yemen closely followed by the Sultanate of Oman are higher than the prevailing fertility rates in the Middle Eastern and North African states (DHS, 1997). Yemen is one of the poorest countries in the world and it now has the highest growth rate.

Total fertility in Yemen is greater than seven children per women of reproductive age. The age at marriage in Yemen is among the lowest in the Arab region. Yemeni women tend to marry early. The first birth interval, duration between marriage and the birth of the child, is shorter than the first birth interval prevailing in any of the Middle Eastern countries (Eltigani, 2001 a). Yet fertility has declined in Yemen. Rashad (2000) attributes the decline to slight increases in the age at marriage while Eltigani (2001b) attributes the same to decline in marital fertility. This paper has three objectives. First is to assess the extent of fertility decline in Yemen during the last decade. Second, to examine the extent of influence of the three components of fertility, age at marriage, extent of modern contraceptive use and the level of abortion on fertility and, finally to explore the impact of a selected set of demographic and socio-economic variables on the three fertility components.

\section{Variables}

Demographic studies have long utilized the proximate determinants proposed by Davis and Blake (1956) as variables for explaining fertility. They provide eleven variables associated with three stages of fertility: intercourse, conception and gestation. Successful passage through the three sequential stages is necessary for the occurrence of fertility related outcomes. Thus the three important components of fertility are age at marriage, modern contraceptive use and abortion. 
Two variables that have widespread empirical support for their influence on age at marriage are place of residence and educational level of the wife at the time of marriage (Hirschman, 1985; Pillai, 1985; Singh, Casterline and Cleland, 1985; Maihotra and Tsui, 1996; Singh and Samara, 1996). Women are more likely to delay marriage in urban areas than in rural. Schooling results in the postponement of marriage. Increases in the number of years of schooling are likely to increase the age at marriage. For educated women, the presence of several competing alternatives to marriage often result in the postponement of marriage. In addition, a "region" variable is included. This is because north and south Yemen were separate countries until their unification. The socio-political events and policies that shaped the life chances of currently married women are not similar across all regions of residence.

The factors which influence contraceptive use include the determinants of age at marriage. The variables, place of residence, and wife's education are associated with contraceptive use. In addition, contraceptive use is also influenced by a number of characteristics that couples bring into marriage. Husband's characteristics such as occupational status (Gauthier and Hatzius, 1997; Hollerbach, 1983), and husband's approval for contraceptive use (Ezeh, 1991) have been found to influence contraceptive use. Most studies show that the educational level of the wife is more strongly and inversely correlated with family size than is the educational level of the husband after controlling for other influences (Cleland, and Rodriguez, 1988). Educated husbands and wives are more likely to discuss desired family size and birth spacing and also use modern contraceptives (Lasee and Becker, 1997). Husband's disapproval is considered as one of the major reasons for non-use of contraceptives in some countries in sub-Saharan Africa (Ezeh, 1991, 1993). The decision to use contraceptives is contingent on whether an additional child is desired. Those who desire additional children are less likely to use modern contraceptives. The variable "desire for additional children" is included in the set of demographic determinants considered in this study.

Factors that influence abortion status include the determinants of age at marriage and contraceptive use. The decision to have an abortion or not is conditioned by the amount of control women have on other aspects of family formation such as age at marriage and contraceptive use. The conditions under which abortion is often obtained have implications for outcomes with respect to women's health. Like many other Muslim nations in this region, use of abortion is not as widely discussed concept in Yemen. Prior to unification, abortion was prohibited except in situations to save the life of the mother. Because of conservative theological and political opinions on abortion that discourage public discussion and the existence of restrictive abortion laws prior to unification, it is hard to estimate the extent of prevalence of abortion (Potts and Masho, 1995). For these reasons, 
Age at Marriage, Contraceptive Use and Abortion in Yemen, 1991-1997

literature on abortion in Yemen is very limited (Weeks, 1988). Questions on abortion in Yemen National surveys such as the 1997 Demographic and Health Survey do not distinguish between spontaneous and induced abortions. Abortion estimates obtained from these sources may not be fully reliable. However, several studies on abortion (Bankole, Singh, and Haas, 1999; Henshaw, Singh, and Haas, 1999; Bairagi, 2001) suggest that particularly in countries where use of contraception is restricted, abortion is used to limit family size (Georges, 1996; Johnson, Horga, and Andronache, 1996).

As education increases, women are less likely to obtain illegal abortion, as they are more aware of the dangers associated with illegal abortion. In Yemen abortion is considered a violation of religious moral codes. Employment in professional occupations increases the undesirability of abortion. Social and economic institutions may perceive violators of moral codes as threats to their institutions. Professional jobholders are less likely to engage in illegal abortion as health risks associated with illegal abortion may disrupt career stability and mobility. Husband's approval of contraceptives brings about an environment supportive of the wife's reproductive health decisions. Thus, the decision to have an abortion may be supported by husband's favorable attitude toward family planning. The desire to have another child reduces the likelihood of abortion. The variable "desire to have another child" is used as a control. In sum, this study suggests that the three determinants of fertility are influenced by contextual variables such as place of residence, human capital variables such as education, labor force participation status, and attitude toward birth control in general. Figure 1 presents the expected model of fertility for Yemen.

\section{Data and Methods}

This study uses data from Demographic and Health Surveys (DHS) conducted in Yemen. The Republic of Yemen had two national surveys conducted - in 1991/1992 and 1997. The 1997Yemen Demographic and Maternal and Child Health Survey (YDMCHS) is the second national survey conducted in Yemen since unification of the country. The YDMCHS- 1997 was designed to collect data on households, and ever-married women of reproductive age (15-49). This survey interviewed 10,414 of the 11,158 eligible ever-married women in the age group 15-49 (Central Statistical Organization (CSO)[Yemen] and Macro International Inc. (MI), 1998). The survey conducted during 1991/1992 interviewed 5687 eligible women (Central Statistical Organization (CSO)[Yemen], Pan Arab Project for Child Development (PAPCHILD)[Egypt], and Macro International Inc. (MI), 1994). The subjects covered in the household survey include characteristics of households, housing and living conditions, school enrollment, labor force participation, general mortality, disability, 
Figure 1. Model of Fertility in Yemen

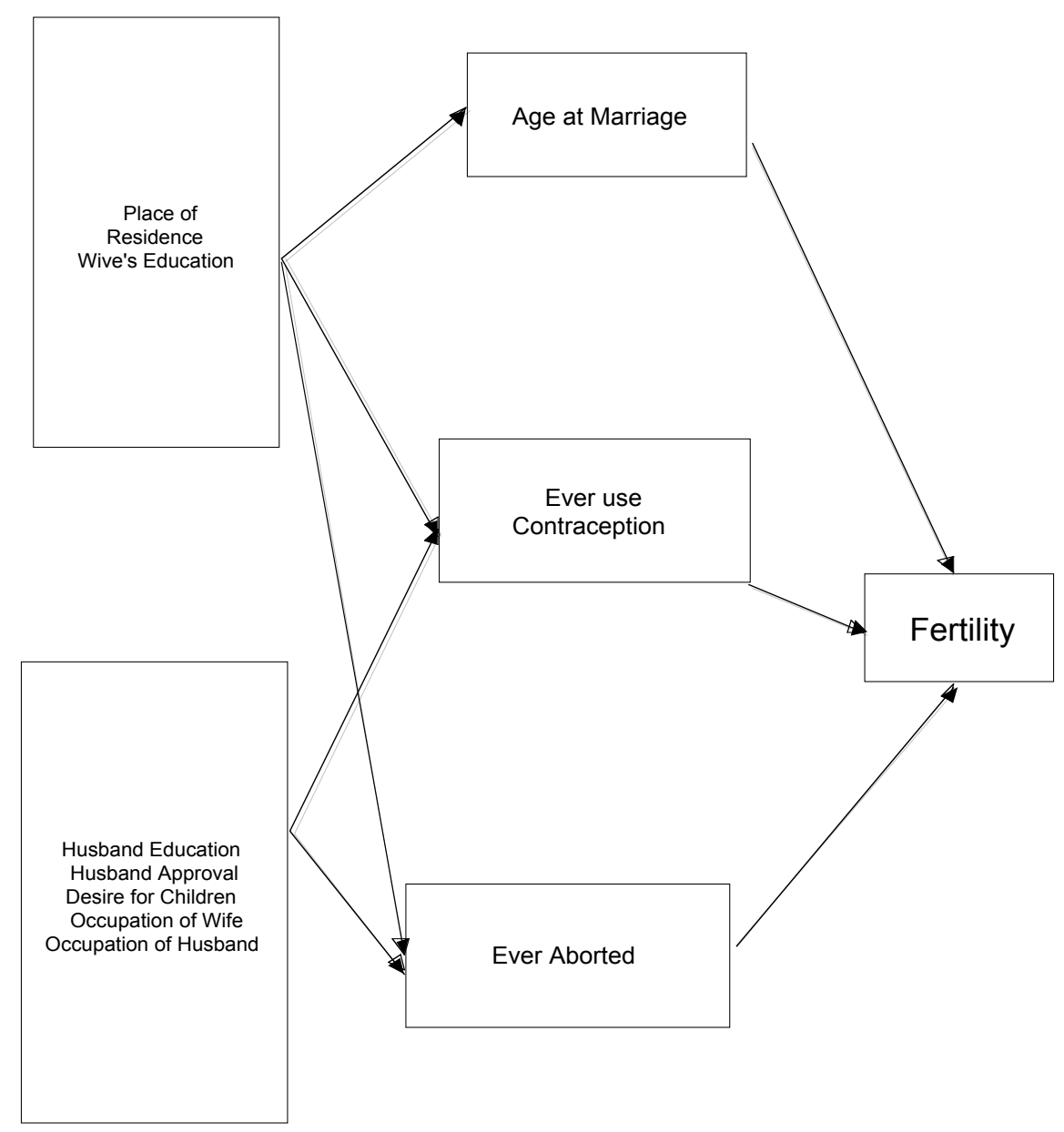

Model of Fertility in Yemen 
Age at Marriage, Contraceptive Use and Abortion in Yemen, 1991-1997

fertility, and child survival. The areas covered in the survey of women of reproductive age are: demographic and socioeconomic characteristics, marriage and reproductive history, fertility regulation and preferences, antenatal care, breastfeeding, and childcare. The main purpose of the 1997 YDMCHS was to provide detailed information on fertility, family planning, infant and child mortality, maternal and child health, and nutrition. The 1997 YDMCHS included a module to obtain information on female circumcision and information was also collected on height and weight of mothers to measure maternal malnutrition.

Responses from the "Maternal and Child Health Questionnaire" module are used in the present study. This module includes several sections - respondent's background, reproduction, family planning, pregnancy and breastfeeding, immunization and health, fertility preferences, marriage, and husband's background, woman's work, maternal mortality, female circumcision, and height and weight. Descriptions and coding of variables used in the study are given in Table 1.

\section{Analysis and Results}

The analysis is conducted in three separate stages. In the first stage, descriptive characteristics of all the variables used in this study are examined. In the next stage, the focus is on the direction of the effects of the three proximate determinants, age at marriage, contraceptive use and abortion status on family size, measured as children ever- born. Family size is regressed on the three determinants. In the final stage, we assess the effects of the selected set of demographic determinants on the three proximate determinants of fertility. Since the dependent variables are categorical in nature, logistic regression is used. The analysis involving all three stages is conducted separately for the 1991 YDHS and 1997 YDHS separately. This provides an opportunity to assess the direction of changes in two sets of relationships. First, between the proximate determinants and family size. Second, between the selected set of demographic variables and the three proximate determinants.

The mean number of children ever-born for the 1991 YDHS is 4.96 children and the median is 5. The mean and median values for the 1997 YDHS data are 4.83 and 4.00 children respectively. Thus there has been a decline, at least by one child, during the 1991-1997 period. Table 1 presents the percentage distribution of all the variables used in the study for the 1991 and 1997 samples. Nearly three-fourth of the 1991 sample respondents lived in rural areas. The difference in the percentages living in rural areas in the 1991 and 1997 is small, about 3 points. 


\section{T. S. Sunil and Vijaya K. Pillai}

Table 1

Percent Distribution of the Covariates associated with the Risk of Births

Ghana and Kenya: 1998

\begin{tabular}{|c|c|c|c|c|c|c|c|}
\hline \multirow{2}{*}{\multicolumn{2}{|c|}{ Covariates }} & \multicolumn{3}{|c|}{ Ghana } & \multicolumn{3}{|c|}{ Kenya } \\
\hline & & $\begin{array}{l}\text { Second } \\
\text { Birth }\end{array}$ & $\begin{array}{l}\text { Third } \\
\text { Birth }\end{array}$ & $\begin{array}{c}\text { Fourth } \\
\text { Birth }\end{array}$ & $\begin{array}{l}\text { Second } \\
\text { Birth }\end{array}$ & $\begin{array}{l}\text { Third } \\
\text { Birth }\end{array}$ & $\begin{array}{c}\text { Fourth } \\
\text { Birth }\end{array}$ \\
\hline \multicolumn{8}{|c|}{ Sex Composition of Surviving Children } \\
\hline All girls & & 47.30 & 15.80 & 25.00 & 50.30 & 38.50 & 49.00 \\
\hline Mixed & & -- & 33.80 & 55.00 & -- & 41.80 & 19.00 \\
\hline All boys & & 52.70 & 42.00 & 20.00 & 49.70 & 19.60 & 25.00 \\
\hline \multicolumn{8}{|l|}{ Birth Cohort } \\
\hline After 1972 & & 14.00 & 6.20 & 2.50 & 18.40 & 9.60 & 4.10 \\
\hline $1962-1972$ & & 44.00 & 15.80 & 38.30 & 46.00 & 47.00 & 44.70 \\
\hline Before 1962 & & 42.00 & 33.80 & 59.00 & 36.60 & 43.40 & 49.00 \\
\hline \multicolumn{8}{|l|}{ Age at First Birth } \\
\hline Under 21 years & & 58.00 & 61.00 & 63.20 & 67.30 & 70.00 & 72.00 \\
\hline Over 21 years & & 42.00 & 39.00 & 36.80 & 32.70 & 30.00 & 28.00 \\
\hline \multicolumn{8}{|l|}{ Education } \\
\hline Secondary education & & 36.50 & 32.80 & 30.00 & 22.70 & 20.00 & 16.60 \\
\hline Below Secondary & & 63.50 & 67.20 & 70.00 & 77.30 & 80.00 & 83.40 \\
\hline \multicolumn{8}{|l|}{ Current Residence } \\
\hline Urban & & 27.30 & 25.30 & 22.60 & 14.50 & 13.00 & 10.00 \\
\hline Rural & & 72.70 & 74.70 & 77.40 & 85.50 & 87.00 & 90.00 \\
\hline \multicolumn{8}{|l|}{ Ethnicity } \\
\hline GHANA & KENYA & & & & & & \\
\hline $\mathrm{Ga}$ & Kikuyu & 6.40 & 5.90 & 5.50 & 15.30 & 14.00 & 12.70 \\
\hline Ewe & Kisii & 12.40 & 11.40 & 11.30 & 7.30 & 7.70 & 8.00 \\
\hline Mole-Daghani & Kalejin & 32.60 & 34.60 & 36.40 & 17.60 & 18.40 & 19.30 \\
\hline Others & Luhya & 3.60 & 4.00 & 4.00 & 15.50 & 14.90 & 15.30 \\
\hline Akan & Others & 45.00 & 44.00 & 42.70 & 45.00 & 44.70 & 44.50 \\
\hline \multicolumn{8}{|l|}{ Marital Union } \\
\hline Polygynous & & 25.00 & 26.60 & 27.80 & 26.40 & 26.50 & 27.00 \\
\hline Monogamous & & 62.00 & 61.00 & 60.00 & 63.50 & 64.00 & 64.10 \\
\hline Not married & & 13.00 & 12.40 & 12.20 & 10.10 & 9.50 & 9.00 \\
\hline \multicolumn{8}{|l|}{ Spouse's Residence } \\
\hline Co-residence & & 64.00 & 66.50 & 67.00 & 63.20 & 65.00 & 66.00 \\
\hline Lives elsewhere & & 36.00 & 33.50 & 33.00 & 36.80 & 35.00 & 34.00 \\
\hline \multicolumn{8}{|c|}{ Length of Preceding Birth Interval } \\
\hline Under 19 months & & 8.20 & 8.30 & 8.40 & 17.50 & 28.00 & 16.00 \\
\hline 19-36 months & & 48.00 & 49.00 & 52.00 & 53.40 & 56.60 & 56.00 \\
\hline Above 36 months & & 45.00 & 42.00 & 36.40 & 29.00 & 15.40 & 28.00 \\
\hline TOTAL & & 2757 & 2123 & 1609 & 4618 & 3626 & 2849 \\
\hline
\end{tabular}


Age at Marriage, Contraceptive Use and Abortion in Yemen, 1991-1997

The educational level of husbands in the 1997 sample is higher than the educational level in the 1991 sample. The percentage of husbands with no education in 1991 was 61 and 48 percent in 1997. There was a 13-point decline in the percentage of husbands with no education. The educational level of respondents in the 1997 sample is higher than in 1991. The percentage of respondents with no education in 1991 was 85 percent and in 1997 the percentage was 79 percent. There was a 6-point decline in the percentage of respondents with no education. While the educational levels of husbands and wives showed improvements over time, the educational gains made by husbands is far greater than the gains made by the respondents. The number of points that declined for husbands with no education was 13 while this figure was 6 for the respondents.

The percentage of husbands with no regular work was 34 percent in 1991. This level decreased by nearly 5 points to 29 percent in 1997 . The percentage of husbands in agriculture also declined. Declines in the percentages of those unemployed, and those working in agriculture, was balanced by an increase in percentage of husbands in the professional/service sector in 1997. The percentage of husbands in professional/service was 38.8 percent in 1991. In the 1997 sample survey, this percentage was 45.3 percent. The percentage of respondents with no regular work was 88 percent in 1991. The percentage in agriculture was about 9 percent in 1991 . This level increased by nearly 14 points to 23 in 1997. The percentage of respondents in professional/service jobs is very small, approximately 3 in the 1991 as well as 1997 samples. Thus, women's participation in the labor force improved impressively during the $1991-1997$ period. Percentage of husbands and respondents participating in the labor force improved over time. However, the magnitude of the improvement among the respondents is far greater than similar gains made by husbands. Even though a very high percentage of respondents were unemployed in the 1991, their rate of labor force participation has increased considerably over time.

Nearly 62 percent of the respondents in 1991 expressed a desire to have more children. This percentage is much smaller, 50 percent in the 1997 sample. There is an impressive 12-percentage point difference. The percentage of husbands who do not approve of family planning remained stable at approximately one third of the respondents belonging to each of the two samples. The percentage of husbands who were not sure about contraceptive use was 37 percent in 1991. This percent is 22 in 1997. There is a large difference of approximately 15 percentage points. As the percentage of husbands who are not sure about contraceptive use declined in 1997 from the 1991 level, the percentage of husbands approving contraceptive use increased. In 1991 the percentage of husbands approving family planning was 29 while this figure was 41 in 1997. In general, the percentage of husbands disapproving contraceptive use remained 
the same in 1991 and 1997. However, the proportion approving contraceptive use in 1997 improved considerably from the 1991 level at the expense of those husbands who were not sure about contraceptive use.

The percentage married before the age of 17 was 63 percent in 1991. This percentage remains the same at about 62 percent in 1997. The median ages at marriage for the 1991 and 1997 respondents are 15 and 16 years respectively (not shown in the table). There has been an upward shift, albeit small, in the age at marriage. Even though the modal age at marriage remained the same at 15 years across the two samples, the proportions married at ages less than 18 years in the 1997 sample are smaller than the proportions at similar ages in the 1991 sample. Figure 2 presents the cumulative distribution of the percentage married by age at marriage. The lower tail of the 1997 graph is flatter than the tail of the 1991 graph.

Figure 2

Cumulative Percentage Married by Age of Marriage, Yemen: 1991 and 1997

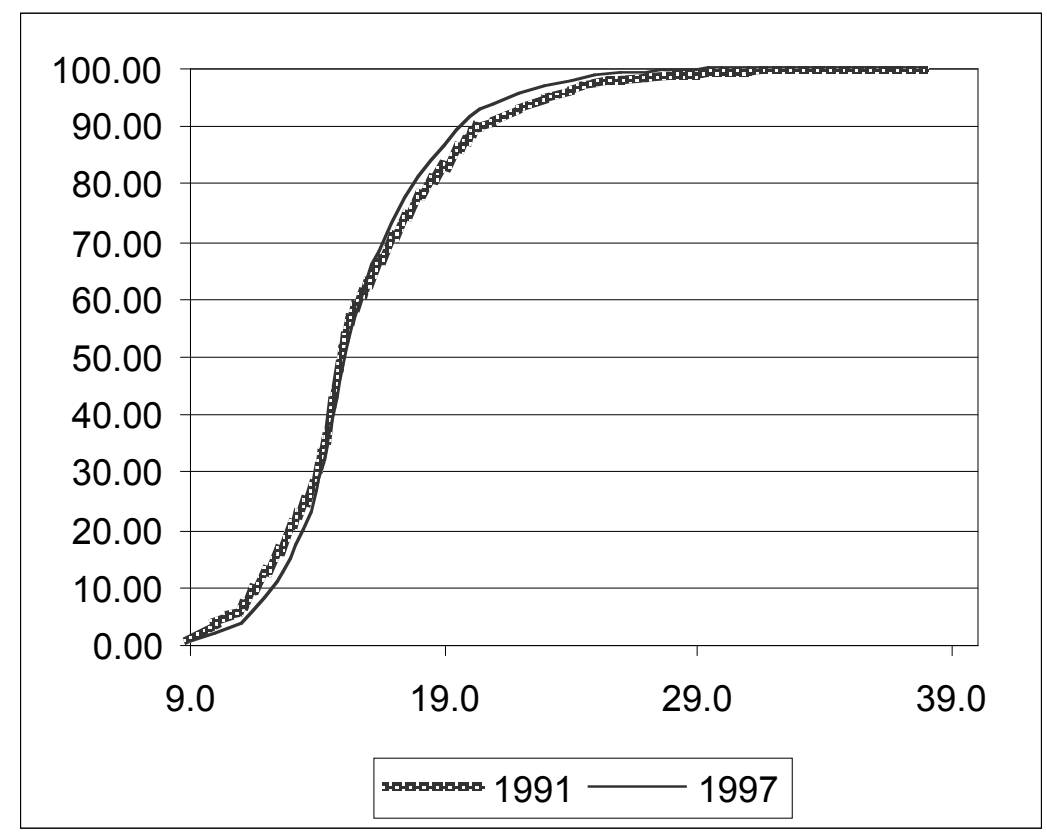


The level of contraceptive use shows change. In 1991, roughly 77 percent of the respondents never used any type of contraception. In 1997, approximately 60 percent of the respondents never used any type of contraception. The percentage of respondents who used some type of contraception increased from 23 to 40 percent in 1997. There is an impressive improvement to the extent of 17 percentage points from the 1991 to the 1997 level.

Figure 3 presents the age-wise distribution of proportion of women using modern contraceptives for the 1991 and 1997 sample. The 1991 values show wide fluctuations from age to age in the proportion using contraception. The 1997 values ascend more sharpely than the 1991 graph and are marked by smaller age-to-age fluctuations.

Figure 3

Rates of Contraceptive Use by Age in Yemen: 1991 and 1997

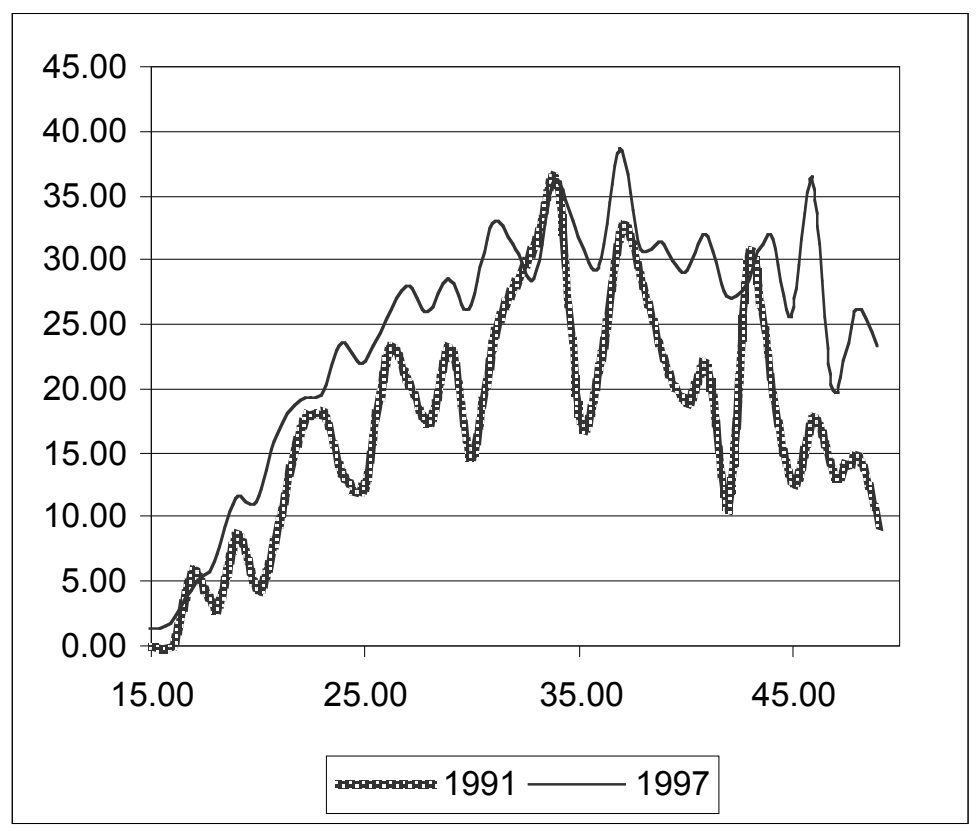




\section{T. S. Sunil and Vijaya K. Pillai}

Approximately one-third of all women aged 34 years from the 1991 and 1997 samples use modern methods. However, the proportion using modern contraceptives beyond age 34 are much higher at most ages in the 1997 sample than the proportions using modern contraception at similar ages in 1991 sample. The upper portion of the 1997 curve remains at a higher level and drops far less rapidly compared with the 1991 curve. The proportions of 1997 YDHS respondents using modern contraception is higher between 34 and 37 years of age. The average number of children ever-born to women in the age range 34-37 years is about six. It appears that use of contraception in general is low and that contraceptive use increases once women have about six children.

The percentage reporting, "ever had abortion" was 31 percent in 1991. The percentage remains approximately the same at 30 percent in 1997. Thus, there was very little change in the level of abortion. The 1991 and 1997 proportions of women who terminated pregnancy increase monotonically with age as would be expected. Figure 4 presents the age-wise distribution of the proportion of women who reported to have ever terminated a pregnancy in the 1991 and 1997 samples.

Figure 4

Abortion Rates by Age in Yemen: 1991 and 1997

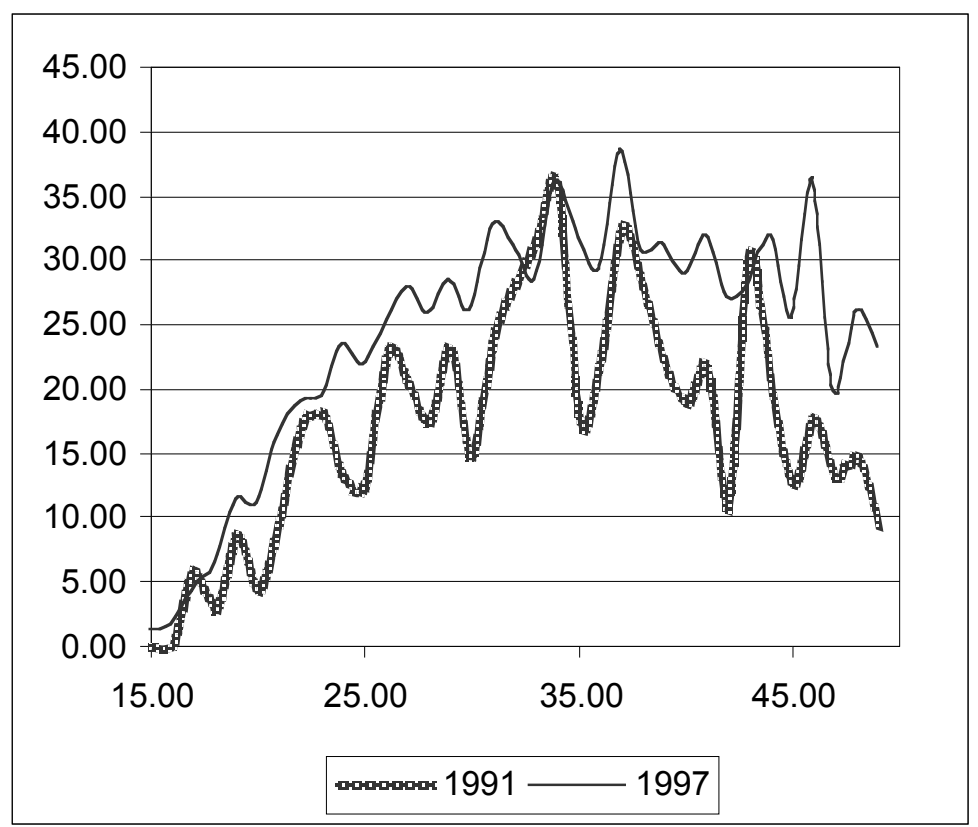


Age at Marriage, Contraceptive Use and Abortion in Yemen, 1991-1997

About 30 percent of the 30 year-olds reported terminated pregnancies in the 1991 sample. Approximately the same percentage of women reported having an abortion at a slightly earlier age, around 25 years, in the 1997 sample. Thus the pace of abortion increased slightly among the young married of the 1997 sample as compared to those in the 1991 sample. In particular, at higher ages, beyond 30 years, the percentages of women who have ever aborted are consistently far greater than the percentages who ever used contraception. At every age, the proportion reporting terminated pregnancies is higher than the proportion who used contraceptives in the 1991 as well as 1997 samples. The importance of abortion as a factor in understanding reproductive health in Yemen is of great importance ${ }^{1}$.

The percentages of 1997 YDHS respondents who reported ever having abortion attains roughly one-third, 33 percent, of respondents at ages 28 years and above. There is a consistent increase in the proportion of women reporting abortion at all ages above 28 years. Women in the 1997 YDHS sample who are 28 years of age have about four children ever born on the average. Roughly half of all women at ages 38 to 39 reported having an abortion. It appears that abortion is a common birth control method among women thirty years of age and older who have already about four to five children.

Table 2 presents the results from the regression of children ever-borne on the three proximate determinants, age at marriage, contraceptive use and abortion status. In this regression, age at marriage is coded 1 if age at marriage is 17 years or later. Respondents who have ever used contraceptives are assigned a code 1 , otherwise 0 . Abortion status is measured at the nominal level. Those who have ever terminated a pregnancy are assigned to a category coded 1 . The rest are coded 0.

The 1991 YDHS respondents who ever had an abortion were 2.7 times more likely to have more than 4 children ever born than those who never had an abortion. Those who have ever used modern contraception were about 60 percent more likely to have more than 4 children than those who never used modern contraception. Age at marriage has a negative influence on number of children ever born as expected. Women who married at age 17 or later are 52 percent less likely to have more than 4 children ever born compared to those who married earlier.

The results from 1997 YDHS are comparable to those from the 1991 sample. The 1997 YDHS respondents who ever had an abortion were 2.7 times more likely to have more than 4 children ever born than those who never had an abortion. Those who have ever used modern contraception were about 90 percent more likely to have more than 4 children than those who never used 
modern contraception. As age at marriage increases, the number of children ever -borne decreases. Women who married at age 17 or later are 61 percent less likely to have more than 4 children ever born than those who married earlier.

As family size increases, both abortion and modern contraceptive use are used to limit family size. However, the use of these methods is limited during the early stages of family building. The influence of abortion as a birth control method remains consistently strong across the two samples. The level of modern birth control methods use is slightly higher among the 1997 sample respondents than among respondents in the 1991 sample. The negative influence of age at marriage on children ever born in the 1997 sample is stronger than in the 1991 sample. In general, increases in age at marriage have contributed to fertility decline. The use of modern contraceptives is gaining momentum especially among those who have four or more children. Abortion appears to be the primary strategy for birth control.

Table 2

Logistic Regression on Children Ever Born (4 or Greater) on Age at Marriage, Modern Contraceptive Use and Abortion Status, Yemen : 1991 YDHS and 1997 YDHS

\begin{tabular}{l|c|c|c|c}
\hline \multirow{2}{*}{ Variables } & \multicolumn{2}{|c|}{$1997^{*}$} & \multicolumn{2}{c}{$1991^{\S}$} \\
\cline { 2 - 5 } & $\operatorname{Exp}(\beta)$ & $\begin{array}{c}\text { Std. } \\
\text { Error }\end{array}$ & $\operatorname{Exp}(\beta)$ & $\begin{array}{c}\text { Std. } \\
\text { Error }\end{array}$ \\
\hline $\begin{array}{l}\text { Age at marriage } \\
(0=<17) \mathrm{t}\end{array}$ & $0.395^{* *}$ & 0.061 & $0.487^{* *}$ & 0.072 \\
$\begin{array}{l}\text { Modern Contraceptive } \\
\text { Use (0=No use) }\end{array}$ & $1.914 * *$ & 0.052 & $1.597 * *$ & 0.0797 \\
$\begin{array}{l}\text { Abortion } \\
(0=\text { Never })\end{array}$ & $2.747^{* *}$ & 0.046 & $2.729 * *$ & 0.064 \\
\hline
\end{tabular}

$\ddagger$-2loglikelihood $=13118$; Nagelkerke $\mathrm{R}$ square $=0.131$

$\S$-2loglikelihood $=7542 \quad$ Nagelkerke $R$ square $=0.102$

$* * \mathrm{p}<.05$ 
Age at Marriage, Contraceptive Use and Abortion in Yemen, 1991-1997

Table 3 presents the results from three regressions using the 1991 data. The dependent variables are age at marriage, contraceptive use and abortion respectively, all measured nominally. The first panel present results from the regression of age at marriage. The second panel reports estimated parameters from the regression of contraceptive use on selected independent variables. The last panel reports results from the regression of abortion status on the chosen determinants.

Among the respondents in the 1991 sample, place of residence has no effect on age at marriage. Wives with some education are at least twice as likely to marry at 17 years of age or later than those who have no education. The effect is significant at the .05 level or less. Urban residents in the 1991 sample are at least three times as likely to have ever used contraceptive compared to rural residents. Contrary to expectation, neither wife's education nor husband's education has a significant effect on ever use of contraception. However husband's approval has significant and strong influence on contraceptive use status. Respondents who have husband's approval are about 15 times more likely to have ever used contraceptive compared to those who do not have husband's approval. Contrary to expectations, wives who are involved in professional job/services are not significantly different from the rest of respondents in terms of their likelihood of contraceptive use. Husband's participation in professional job/service significantly increases the likelihood of having ever used contraception.

Few of the selected variables in this study have an effect on abortion status. Urban residents are significantly more likely to have terminated a pregnancy than rural residents. The effect is significant at the .001 level. Respondents whose husbands have some education are significantly less likely to have ever terminated a pregnancy compared with wives whose husbands have no education. Further more, wives with some education are significantly less likely to have ever terminated a pregnancy compared with wives who have no education. The only other determinant with an effect on the likelihood of pregnancy termination is husband's approval. Husband's approval of family planning significantly increases the likelihood of abortion.

Table 4 presents the results from three regressions using the 1997 data. The dependent variables are categories of age at marriage, contraceptive use and abortion status respectively. The coding scheme used for all three dependent variables is the same as the one utilized in the regression analysis of 1991 data. The first panel present results from the regression of age at marriage. The second panel reports estimated coefficients from the regression of contraceptive use on selected determinants. The last panel reports results from the regression of abortion status on the chosen independent variables. 


\section{T. S. Sunil and Vijaya K. Pillai}

Table 3

Cox Model of Covariates Associated with Third Births, Ghana and Kenya: 1998

\begin{tabular}{|c|c|c|c|c|c|c|}
\hline \multirow{2}{*}{ Covariates } & \multicolumn{3}{|c|}{ Ghana } & \multicolumn{3}{|c|}{ Kenya } \\
\hline & Model 1 & Model 2 & Model 3 & Model 1 & Model 2 & Model 3 \\
\hline \multicolumn{7}{|l|}{ Status of Child } \\
\hline First child died in infancy & $1 . .35 * * *$ & $1.28^{* * *}$ & $1.32 * * *$ & $1.22 * * *$ & $1.12^{*}$ & $1.16^{* *}$ \\
\hline Survived (reference) & $\mid 1.00$ & 1.00 & 1.00 & 1.00 & 1.00 & 1.00 \\
\hline Second child died in infancy & $2.48^{* * *}$ & $1.80^{* * *}$ & $1.93^{* * *}$ & $2.19 * * *$ & $1.67 * * *$ & $1.72^{* * *}$ \\
\hline Survived (reference) & & 1.00 & 1.00 & 1.00 & 1.00 & 1.00 \\
\hline \multicolumn{7}{|l|}{ Birth Cohort } \\
\hline After 1972 & & $0.09 * * *$ & $0.11^{* * *}$ & & $0.11 * * *$ & $0.14^{* * *}$ \\
\hline $1962-1972$ & & $0.60^{* * *}$ & $0.59^{* * *}$ & & $0.70^{* * *}$ & $0.69^{* * *}$ \\
\hline Before 1962 (reference) & & 1.00 & 1.00 & & 1.00 & 1.00 \\
\hline \multicolumn{7}{|l|}{ Age at First Marriage } \\
\hline Under 21 years & & $1.72 * * *$ & $1.60^{* * *}$ & & $2.04 * * *$ & $1.64 * * *$ \\
\hline Over 21 years (reference) & & 1.00 & 1.00 & & 1.00 & 1.00 \\
\hline \multicolumn{7}{|l|}{ Education } \\
\hline Secondary education & & $0.61^{* * *}$ & $0.62 * * *$ & & $0.82 * * *$ & $0.78^{* * *}$ \\
\hline Below Secondary (reference) & & 1.00 & 1.00 & & 1.00 & 1.00 \\
\hline \multicolumn{7}{|l|}{ Residence } \\
\hline Urban & & $0.79 * * *$ & $0.83^{* * *}$ & & $0.66 * * *$ & $0.74 * *$ \\
\hline Rural (reference) & & 1.00 & 1.00 & & 1.00 & 1.00 \\
\hline \multicolumn{7}{|l|}{ Ethnicity } \\
\hline GHANA & & & & & & \\
\hline Kikuyu & & & 1.00 & & & $0.89^{*}$ \\
\hline Kisii & & & 0.91 & & & 1.01 \\
\hline Mole-Daghani & & & $0.75^{* * *}$ & & & $1.14^{* *}$ \\
\hline Others & & & 1.04 & & & 1.14 \\
\hline Akan (reference) & & & 1.00 & & & 1.00 \\
\hline \multicolumn{7}{|l|}{ Type of Marital Union } \\
\hline Polygynous & & & $0.84^{*}$ & & & 0.93 \\
\hline Not married & & & $0.80^{* * *}$ & & & $0.64 * * *$ \\
\hline Monogamous (reference) & & & 1.00 & & & 1.00 \\
\hline \multicolumn{7}{|l|}{ Spouse's Residence } \\
\hline Co-residence & & & $1.20^{* * *}$ & & & 0.97 \\
\hline Lives elsewhere (reference) & & & 1.00 & & & 1.00 \\
\hline \multicolumn{7}{|l|}{ Length of Preceding Birth Interval } \\
\hline Under 19 months & & & 1.07 & & & $1.19^{* * *}$ \\
\hline Above 36 months & & & $0.55^{* * *}$ & & & $0.49^{* * *}$ \\
\hline $19-36$ months & & & 1.00 & & & 1.00 \\
\hline \multicolumn{7}{|l|}{ Sex Composition of Surviving Children } \\
\hline All girls & & & $1.41^{* * *}$ & & & $1.28^{* * *}$ \\
\hline Mixed & & & $1.32 * * *$ & & & $1.26^{* * *}$ \\
\hline All boys & & & 1.00 & & & 1.00 \\
\hline -2 Log Likelihood & 32882 & 31605 & 31304 & 59392 & 56932 & 56357 \\
\hline Chi-Square & 125 & 1403 & 1704 & 137 & 2547 & 3172 \\
\hline Degrees of Freedom & 2 & 7 & 18 & 2 & 7 & 18 \\
\hline Significance & 0.000 & 0.000 & 0.000 & 0.000 & 0.000 & 0.000 \\
\hline
\end{tabular}


Age at Marriage, Contraceptive Use and Abortion in Yemen, 1991-1997

Place of residence has no effect on age at marriage. Wives with some education are at least twice as likely to marry at 17 years of age or later than those who have no education. The effect is significant at the 0.001 level. Urban residents are at least two times as likely to have ever used contraceptives compared to rural residents.

Contrary to expectation, wife's education has no positive effect on the likelihood of having ever used contraception. Husband's education has a significant negative effect on contraceptive use. Husband's approval has a significant and strong influence on contraceptive use status. Respondents who have husband's approval are about 6 times more likely to have ever used contraceptives compared to those who do not have husband's approval. As expected, wives who are involved in professional job/services are more likely to have ever used contraception. This effect is significant even though the magnitude of the effect is small. Respondents who hold professional job/service are only 46 percent more likely to have ever used contraception compared to respondents who do not work outside the home. Husband's participation in professional job/service significantly increases the likelihood of having ever used contraception.

A few of the selected determinants in this study have an effect on abortion status. Urban residents are significantly more likely to have terminated a pregnancy than rural residents. The effect is significant at the 0.001 level. Respondents whose husbands have some education are significantly less likely to have ever terminated a pregnancy compared with wives whose husbands have no education. Furthermore, wives with some education are significantly less likely to have ever terminated a pregnancy compared with wives who have no education. The only other determinant with an effect on the likelihood of pregnancy termination is wife's occupational status. Respondents who are employed in professional/service sector or self employed in the agricultural sector are significantly more likely to have ever aborted than wives who do not work outside the home. Thus, as education decreases the likelihood of abortion and employment tends to increase the likelihood of abortion.

The comparison of the results from the three regressions for the 1991 and 1997 samples show remarkable stability. While place of residence is not a significant factor, wife's educational level significantly influences age at marriage. Urban residents are significantly more likely to use contraceptives than rural among 1991 and 1997 sample respondents. Husband's education has no significant effect on ever use of contraception in the 1991 sample. However, its effect is significant and negative in the 1997 sample. . The effect of wife's education on ever use of contraception are similar across the two samples. Wife's education has no significant effect on ever use of contraception in the 1991 as well as the 1997. The effect of husband's professional status is similar across the two 


\section{T. S. Sunil and Vijaya K. Pillai}

Table 4

A Cox Model of Covariates Associated with the Risk of Fourth Births, Ghana and Kenya: 1998

\begin{tabular}{|c|c|c|c|c|c|c|}
\hline \multirow[b]{3}{*}{ Covariates } & \multicolumn{3}{|c|}{ Ghana } & \multicolumn{3}{|c|}{ Kenya } \\
\hline & \multicolumn{3}{|c|}{ Hazard Ratios } & \multicolumn{3}{|c|}{ Hazard Ratios } \\
\hline & Model 1 & Model 2 & Model 3 & Model 1 & Model 2 & Model 3 \\
\hline \multicolumn{7}{|l|}{ Status of Child } \\
\hline First child died in infancy & $1.32^{* * *}$ & $1.29^{* * *}$ & $1.60^{* * *}$ & $\mid 1.24 * * *$ & $1.15^{*}$ & $1.11^{*}$ \\
\hline Survived (reference) & $\mid 1.00$ & 1.00 & 1.00 & $\mid 1.00$ & 1.00 & 1.00 \\
\hline Second child died in infancy & $\mid 1.72^{* * *}$ & $1.49^{* * *}$ & $1.42 *$ & || $1.46^{* * *}$ & $1.14 !$ & 1.04 \\
\hline Survived (reference) & $\mid 1.00$ & 1.00 & 1.00 & $\mid 1.00$ & 1.00 & 1.00 \\
\hline Third child died in infancy & $3.14^{* * *}$ & $1.89^{* * *}$ & $1.94 * * *$ & | $2.88^{* * *}$ & $1.81 * * *$ & $1.62 * * *$ \\
\hline Survived (reference) & 1.00 & 1.00 & 1.00 & $\mid 1.00$ & 1.00 & 1.00 \\
\hline \multicolumn{7}{|l|}{ Birth Cohort } \\
\hline After 1972 & & $0.03 * * *$ & $0.05^{* * *}$ & & $0.04 * * *$ & $0.10^{* * *}$ \\
\hline $1962-1972$ & & $0.40^{* * *}$ & $0.45^{* * *}$ & & $0.55 * * *$ & $0.62 * * *$ \\
\hline Before 1962 (reference) & & 1.00 & 1.00 & & 1.00 & 1.00 \\
\hline \multicolumn{7}{|l|}{ Age at First Marriage } \\
\hline Under 21 years & & $2.02 * * *$ & $1.76^{* * *}$ & & $2.15^{* * *}$ & $1.60^{* * *}$ \\
\hline Over 21 years (reference) & & 1.00 & 1.00 & & 1.00 & 1.00 \\
\hline \multicolumn{7}{|l|}{ Education } \\
\hline Secondary education & & $0.58^{* * *}$ & $0.68^{* * *}$ & & $0.72 * * *$ & $0.75^{* * *}$ \\
\hline Below Secondary (reference) & & 1.00 & 1.00 & & 1.00 & 1.00 \\
\hline \multicolumn{7}{|l|}{ Residence } \\
\hline Urban & & $0.71^{* * *}$ & $0.75^{* *}$ & & $0.53 * * *$ & $0.66^{* *}$ \\
\hline Rural (reference) & & 1.00 & 1.00 & & 1.00 & 1.00 \\
\hline \multicolumn{7}{|l|}{ Ethnicity } \\
\hline GHANA & & & & & & \\
\hline Kikuyu & & & 1.00 & & & $0.87^{*}$ \\
\hline Kisii & & & 0.96 & & & $1.15^{*}$ \\
\hline Mole-Daghani & & & $0.90^{*}$ & & & $1.24^{* * *}$ \\
\hline Others & & & 0.97 & & & 1.07 \\
\hline Akan (reference) & & & 1.00 & & & 1.00 \\
\hline \multicolumn{7}{|l|}{ Type of Marital Union } \\
\hline Polygynous & & & 0.97 & & & 0.99 \\
\hline Not married & & & $0.80^{* * *}$ & & & $0.93 *$ \\
\hline Monogamous (reference) & & & 1.00 & & & 1.00 \\
\hline \multicolumn{7}{|l|}{ Spouse's Residence } \\
\hline Co-residence & & & $1.32^{* * *}$ & & & $1.12 *$ \\
\hline Lives elsewhere (reference) & & & 1.00 & & & 1.00 \\
\hline \multicolumn{7}{|l|}{ Length of Preceding Birth Interval } \\
\hline Under 19 months & & & $1.32^{* * *}$ & & & $1.10^{*}$ \\
\hline Above 36 months & & & $0.42^{* * *}$ & & & $0.45^{* * *}$ \\
\hline $19-36$ months & & & 1.00 & & & 1.00 \\
\hline \multicolumn{7}{|l|}{ Sex Composition of Surviving Children } \\
\hline All girls & & & $1.65^{* * *}$ & & & $3.17^{* * *}$ \\
\hline Mixed & & & $1.61^{* * *}$ & & & $2.66^{* * *}$ \\
\hline All boys & & & 1.00 & & & 1.00 \\
\hline-2 Log Likelihood & 25202 & 23797 & 23335 & 47166 & 44433 & 43317 \\
\hline Chi-Square & 285 & 1592 & 2054 & 212 & 2944 & 4061 \\
\hline Degrees of Freedom & 3 & 8 & 19 & 3 & 8 & 19 \\
\hline Significance & 0.000 & 0.000 & 0.000 & 0.000 & 0.000 & 0.000 \\
\hline
\end{tabular}


Age at Marriage, Contraceptive Use and Abortion in Yemen, 1991-1997

samples. Wife's professional occupation status has no significant influence on contraceptive use in the 1991 sample. However its effect is positive and significant in the 1997 sample. Thus effects of wives' characteristics, in particular her professional job status, is considerably more significant in terms of its influence on modern contraceptive use than its effects on contraceptive use in 1991. Husband's approval had a strong positive effect among the 1991 sample respondents. This effect stays strong and positive among the 1997 sample respondents.

Place of residence has a positive effect on ever aborted status among the 1991 and 1997 sample respondents. The effects of husband's education and wife's education on abortion are significant and negative in both samples. Husband's approval of family planning significantly increased the likelihood of abortion among 1991 sample respondents. Its effect on ever-aborted status is not significant for the 1997 sample respondents. Husband's professional occupational status has no effect on abortion status across the two samples. Wife's employment outside the home, or employed in professional job/ service sector, significantly increased the likelihood of having ever terminated a pregnancy in the 1997 sample while the effects of this variable were not significant for the 1991 sample respondents.

\section{Conclusion and Discussion}

Fertility rates in Yemen closely followed by the Sultanate of Oman are higher than the prevailing fertility rates in the Middle Eastern and North African states. This region presents high variation in total fertility rates. The duration as well as the pace of fertility decline varies considerably. There is widespread consensus about the root cause of this decline. Rashad (2000) and Courbage (1992) suggest that the most important determinant of fertility decline is an increase in age at marriage. Marriage is nearly universal. Young women are attaining higher levels of education resulting in the postponement of marriage. Contraceptive use within marriage during the first few years of family formation is very low. Knowledge of modern methods of contraception is high. Prevalence of contraceptives increases slowly over the birth orders higher than three (Courbage, 1992).

It is well known that fertility declines in Arab nations have resulted from a range of strategies that mix changes in a number of intermediate determinants of fertility such as age at marriage, contraceptive use, and prevalence of breast feeding. A cursory review of literature on Arab fertility transition reveals that abortion is seldom considered as a means of fertility control. This lack of attention to abortion perhaps results from a bias in favor of cultural explanations 
of Muslim fertility.

We find increases in age at marriage, contraceptive use, and stable levels of abortion. Fertility in Yemen has declined during the last decade. The median number of children ever born for the 1991/92 and 1997 YDHS are 5 and 4 respectively. Thus, there has been a decline, at least by one child, during the 1991-1997 period. This is a remarkable decline of twenty percent of the initial 1991 family size. Results from this study suggest that increase in age at marriage has contributed significantly to this decline. There has also been an increase in modern contraceptive use during the last decade. However, modern methods are not widely used at early stages of family formation. Improving women's education is of great importance. In particular, improving women's education delays marriage and reduces the likelihood of abortion. There is some evidence that it also improves contraceptive use. The effects of husband's education and wife's education on age at marriage and abortion are very similar. Urban residents are more likely to use contraception and also resort to abortion than rural residents.

Even though wife's education had no significant impact on contraceptive use among the 1991 YDHS respondents, its effect on contraceptive use among the 1997 sample was significant. There is some evidence (for 1997 YDHS only) that wife's employment, especially in the professional services, improves modern contraceptive use and also increases the likelihood of abortion. Husband's employment in professional services, on the other hand improves contraceptive use but has no effect on wife's abortion status. Husband's approval of family planning significantly improves contraceptive use but has no influence on abortion status. Thus, within marriage changes in familial roles involving wife's participation in modern sectoral jobs tends empower her to make contraceptive decisions. At a broad level, improvements in women 's education as well as modern sectoral labor force participation may enable women to increase their capacity to make decisions with respect to contraceptive use as well as abortion.

Education has a negative effect on the likelihood of having abortion. When women opt not to abort, fertility level may increase. This study finds that the level of abortion is high in the Republic of Yemen. At least during the last decade, abortion levels have not changed noticeably. Abortion as a method of control is widespread. Family planning programs must reach women before they have unplanned pregnancies. In addition, there is an immediate need to address the health related issues associated with high abortion levels. Given the evidence of the practice of abortion as a method of family limitation, it is likely that a large proportion of women suffer from undesirable health consequences, including maternal deaths, of illegal abortions. Utilization of reproductive health services is low. In the MENA countries, less than 70 percent of pregnant women 
Age at Marriage, Contraceptive Use and Abortion in Yemen, 1991-1997

receive antenatal check up (Roudi-Fahimi, 2003). Currently, the demand for abortion among women (1997 YDHS data) employed in the modern sector is high. In the short run, if these women are to be discouraged from having an abortion, programs and policies are necessary to reduce the cost of having an unplanned child. At present very little is known with regard to the nature of this conflict. Studies are needed to investigate the nature of the division of labor with regard to caregiving, especially childcare in the Yemeni society. Unless data are available on the cultural components of childe care and child rearing it is not possible to design programs for reducing the work - child-rearing conflict.

The family setting remains strongly traditional. At a broad level, as husbands and wives achieve socioeconomic mobility by gaining education and employment in professional services, they are more likely to delay marriage, and use modern contraceptives. As macro level changes are brought about by increasing women's education and labor force participation, the traditional family will be under considerable pressure to change. The consequences of these pressures on the family are to be investigated.

\section{End Notes:}

1. The dissimilarity index for the 1991 contraceptive use and abortion distributions is 0.154 . The index for the 1997 contraceptive use and abortion distributions is about 0.080 . Thus, 1997 ever-aborted distribution is far similar to the 1997 modem contraceptive distribution than the 1991 ever aborted and 1991 modem contraceptive use distribution. The fall in the dissimilarity indices can be accounted for a sharp increase in the contraceptive use across all ages from 1991 to 1997 and the stability of the abortion levels across 1991 and 1997 sample. The median age of all the respondents who ever terminated pregnancy in the 1997 sample was about an year less than the comparable 1991 median age.

\section{References:}

Bairagi, Radheshyam. 2001. "Effects of sex preference on contraceptive use, abortion and fertility in Matlab, Bangladesh," International Family Planning Perspectives, 27(3): 137-143.

Bankole, Akinrinola., Susheela Singh., and Taylor Hass. 1999. "Characteristics of women who obtain induced abortion: a worldwide view," International Family Planning Perspectives, 25(2): 68-77. 
Central Statistical Organization (CSO) [Yemen], Pan Arab Project for Child Development (PAPCHILD) [Egypt], and Macro International Inc.(MI). 1994. Yemen Demographic and Maternal and Child Health Survey 1991/92. Calverton, Maryland: CSO and MI.

Central Statistical Organization (CSO)[Yemen] and Macro International Inc.(MI). 1994. Yemen Demographic and Maternal and Child Health Survey 1998. Calverton, Maryland: CSO and MI.

Cleland, John., and German Rodriguez. 1988. "The effect of parental educa on on marital fertility in developing countries," Population Studies, 42(3): 419-442.

Courbage, Youssef. 1992. "Demographic transition among Muslims in Eastern Europe," Population: An English Selection, 4(1)161-186.

Davis, Kingsley, and Judith Blake. 1956. "Social structure and fertility," Economic Development and Cultural Change, 4: 211-235.

DHS [Demographic Health Survey], 1997. DHS Working Papers: Reproductive Behavior in Muslim Countries. Maryland: Macro International.

Eltigani, Eltigani. 2001a. "Childbearing in Five Arab Countries," Studies in Family Planning, 32(1):17-24.

Eltigani, Eltigani. $200 \mathrm{lb}$. Levels and Trends of Fertility in Oman and Yemen. Paper Presented at the Workshop on Prospects for Fertility Decline in High Fertility Countries. United Nations Secretariat, New York 9-11. July.

Ezeh, Alex C. 1991. "Gender differences in reproductive orientation in Ghana: A new approach to understanding fertility and family planning issues in sub-Saharan Africa," in Demographic and Health Surveys World Conference: Proceedings, Vol.1, Institute for Resource Development (IRD)/Macro International: Columbia, MD, USA.

Ezeh, Alex C. 1993. "The influence of spouses over each other's contraceptive attitudes in Ghana," Studies in Family Planning, 24(3): 163-174.

Gauthier, Anne Helene., and Jan Hatzius. 1997. "Family benefits and fertility: an econometric analysis," Population Studies, 51(3): 295-306. 
Age at Marriage, Contraceptive Use and Abortion in Yemen, 1991-1997

Georges, Eugenia. 1996. “Abortion policy and practice in Greece,” Social Science and Medicine, 42(4): 509- 519.

Henshaw, Stanley K., Susheela Singh., and Taylar Haas. 1999. "Recent trends in abortion rates worldwide," International Family Planning Perspectives, 25(1): 44-48.

Hirschman, C. 1985. "Premarital socioeconomic roles and the timing of family formation," Demography, 22(1): 35-59.

Hollerbach, Paula E. 1983. Fertility decision-making process: a entical essay, in Rodolfo A. Bulatao and Ronald D. Lee (eds.), Determinants of Fertility in Developing Countries. New York: Academic Press.

Hull, Terence H. 1983. Cultural influences on fertility decision styles, in Rodolfo A. Bulatao and Ronald D. Lee (eds.), Determinants of Fertility in Developing Countries, Volume 2. New York: Academic Press.

Johnson, Brooke R., Mihai Horga., and Laurentia Andronache. 1996. "Women's perspective on abortion in Rornania," Social Science Medicine, 42(4): 521-530.

Lasee, Ashraf., and Stan Becker. 1997. "Husband-wife communication about family planning and contraceptive use in Kenya," International Family Planning Perspectives, 4(1): 2-8.

Malhotra, Anju., and Amy Ong Tsui. 1996. "Marriage timing in Sri Lanka: the role of modern norms and ideas," Journal of Marriage and the Family, 58(2): 476-490.

Pillai, Vij ayan. 1985. "Age at first marriage: a review of recent models in the United States," Journal of Family Welfare, 32(1): 41-49.

Potts, Malcolm., Saba W. Masho. 1995. "Sterilization, contraception, and abortion: global issues for women," Sexual and Marital Therapy, 10(2): 135-147. 
Rashad, Hoda. 1999. Regrouping and Reinterpretation: Fertility in the Arab Countries. Paper Presented at the Seminar on 'Social Categories in Population Health' Organized by the Committee Anthropological Demography of the International Union for the Scientific Study of Population, 15 - 18 September, Cairo, Egypt.

Rashad, Hoda. 2000. "Demographic transition in Arab countries: A new perspective," Journal of Population Research, 17(1): 83-101.

Roudi-Fahimi, Farzaneh. 2003. Women's reproductive Health in Middle-East and North Africa. MENA Policy Brief. Washington D.C : Population Reference Bureau.

Singh, Susheela., J.B. Casterline., and J.G. Cleland. 1985. "The proximate determinants of fertility: Sub-national variations," Population Studies 39(1): 113-135.

Singh, Susheela., and Renee Samara. 1996. "Early marriage among women in developing countries," International Family Planning Perspectives, 22(3): 148-157 \& 175.

Weeks, John. 1988. "The demography of Islamic nations," Population Bulletin, 43(4): 1-53. 